ious surveys, this second task was vital, and just tribute is given to the Sudanese Antiquities Service and their UNESCO adviser, Professor W.Y. Adams, for their organization of the archaeological work.

In Egyptian Nubia, though late sites like Qasr Ibrim and Gebel Adda were of great importance, the task of raising and removing temples was paramount. Abu Simbel, Philae, Kalabshah and Amada receive the fullest treatment, though other salvage operations are accorded their due. The technological and financial problems, and the reasons for the compromise solutions finally adopted, are presented with clarity, judgement and understanding. This section will be a textbook for future collaborative cultural endeavours. SäveSöderbergh emphasizes the equal roles of UNESCO's guidance, of international generosity, and of the collaboration of the Sudan and Egypt; Egypt alone contributed nearly half the cost of rescuing the Abu Simbel and Philae temples - a fact that is not always appreciated.

The account of the archaeological excavations and surveys is again too brief to do complete justice to the variety of the work achieved and the original contributions to scientific knowledge, but several of the most telling examples are described. Some mistakes were undoubtedly made. But the history and archaeology of Nubia were substantially rescued in the limited time available, and the final verdict that the campaign was an "outstanding success" is justified. Those of us who took part will never forget the spirit of camaraderie that prevailed, despite all the difficulties, nor the brave people of Nubia, to whom the final accolade is deservedly given; may future technical triumphs restore them to their beloved land.

H.S. Smith is Edwards Professor in the Department of Egyptology, University College London, Gower Street, London WC1E 6BT, UK.

\section{Physics on a plate}

\section{J.H. Mulvey}

The Quantum Universe. By Tony Hey and Patrick Walters. Cambridge University Press:1987. Pp.180. Hbk £27.50, \$44.50; pbk £9.95, \$16.95.

RICHARD Feynman, the guru pictured at the front of The Quantum Universe and quoted at the start of every chapter, has explained how his formulation of quantum electrodynamics, using the diagrams carrying his name, was the outcome of attempts to understand the motions of a spinning plate. As he told his boss at the time, Hans Bethe, this was an exercise "of no importance whatever, I'm just doing it for the fun of it".

Tony Hey and Patrick Walters believe they should communicate the enjoyment and fascination they find in quantum mechanics to a wider circle of people interested in science by way of a book for their coffee tables. But they also have a more serious intent: to reach those such as the research director of a high-technology firm who has dismissed quantum mechanics as an irrelevancy, so betraying a failure of comprehension which must raise doubts about the future of his enterprise. No reader can fail to be impressed by the way quantum mechanics, replacing newtonian mechanics in the control of particle behaviour at the atomic scale and below, underlies our understanding of the physical world: chemistry, the solid state, microelectronics, lasers, superconductivity, stars and black holes. It is the framework on which physicists construct theories of the forces which have determined the evolution of the Universe from the Big Bang to the present.

A violin string vibrates in a discrete set of modes. The wave-like formulation of quantum mechanics is used to explain the similarly quantized energy levels of electrons in atoms. But this success is bought at the price of a loss of precision in describing the motion of individual particles. This troublesome counter-intuitive behaviour, to which Einstein was never reconciled, is discussed in a clear analysis of the double-slit experiment. As Feynman said ". . . nobody understands quantum mechanics"; but, like the physicists, one has to accept that it works and this the authors marvellously demonstrate, commendably resisting any temptation to indulge in philosophical digressions. Simple mathematical relationships are used sparingly, when they really help to convey a point (the more mathematically inclined are invited to solve Schrödinger's equation in an appendix). The text is liberally supported by excellent pictures and diagrams, and scattered with thumbnail biographies of many leading scientists.

By tackling concepts that might have been considered too difficult for nonspecialists the authors have boldly broken new ground. The pace never slackens and towards the end the double-slit experiment is again used to illustrate the meaning of gauge (or phase) invariance, the principle which seems to be the key to understanding nature's forces. This book will amaze, baffle and delight as it opens up a view of the physicist's secret garden for those happy to make some intellectual effort to appreciate how the world is as it is.

J.H. Mulvey is a Senior Research Officer in the Nuclear Physics Laboratory, University of Oxford, Keble Road, Oxford OXI $3 R H, U K$.

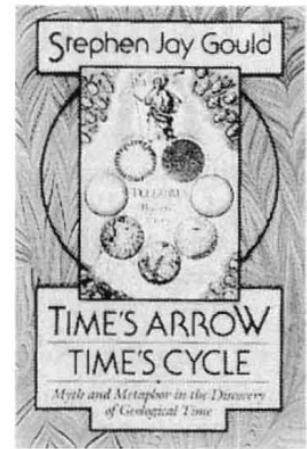

Time's Arrow, Time's Cycle

Myth and Metaphor in the Discovery of Geological Time

STEPHEN JAY GOULD

Gould's subject is geology's signal contribution to human thought - the discovery of "deep time", the vastness of earth's history.

$£ 13.95$ Cloth 240pp illus. 0-674-89198-8 1 May

Metabolic Arrest and the Control of Biological Time

PETER W. HOCHACHKA \&

MICHAEL GUPPY

This pioneering book examines the ability of some animals to regulate their own metabolisms.

$£ 21.95$ Cloth 256pp illus. 0-674-56976-8

\section{Walter B. Cannon}

The Life and Times of a

Young Scientist

SAUL BENISON, A. CLIFFORD

BARGER \& ELIN L. WOLFE

The first biography of one of the 20th century's most distinguished crusaders of medical science.

Belknap £23.95 Cloth 528pp illus.

0-674-94580-8 July

\section{Revolution in Science}

\section{BERNARD COHEN}

'Monumental scholarship... In sheer variety of riches this book has few parallels.' Nature

$£ 7.95$ Paper 736pp illus. 0-674-76778-0

\section{Niels Bohr: A Centenary Volume}

\section{Edited by A. P. FRENCH \&}

\section{P. J. KENNEDY}

'If you have any interest at all in 20thcentury science, then it is essential reading.' New Scientist

$£ 11.95$ Paper 424pp illus. 0-674-62416-5

\section{The Dialectical Biologist}

\section{RICHARD LEVINS \&}

\section{RICHARD LEWONTIN}

an extremely readable and very provocative book.' New Scientist $£ 7.25$ Paper 320pp illus. 0-674-20283-X

\section{The X-Ray Universe}

\section{WALLACE TUCKER \&} RICCARDO GLACCONI

'Scintillating ... the first readable and comprehensive account of the X-ray universe.' Times Higher Education

Supplement

£6.25 Paper 220pp illus. 0-674-96286-9

\section{HARVARD}

\section{UNIVERSITY PRESS}

126 Buckingham Palace Road London SWIW 9SD Reader Service No.28 